\title{
Beneficial effects of Raga therapy in the management of stress among children with type $\mathrm{D}$ personality
}

\author{
Madhusudhan U' ${ }^{1}$, Kumar Sai Sailesh ${ }^{2, *}$, Jabir P K ${ }^{3}$ \\ ${ }^{1,3}$ Assistant Professor, Dept. of Physiology, DMWIMS Medical College, Wayanad, Kerala, ${ }^{2}$ Assistant Professor, Dept. of \\ Physiology, Vishnu Dental College, Vishnupur, Bhimavaram, Andhra Pradesh, India \\ *Corresponding Author: \\ Email: saisailesh.kumar@gmail.com
}

Received: $19^{\text {th }}$ March, 2018

Accepted: $7^{\text {th }}$ June, 2018

\begin{abstract}
Introduction: Om chanting and Ragas for stress alleviation. Different Ragas are likewise observed to be exceptionally compelling in overseeing or curing illnesses. In such conduct, a blend of particular notes or Ragas is being utilized to follow up on a specific chakra.

Aims and Objectives: The present study was undertaken to observe the effect of Raga therapy in the treatment of stress. Materials and Methods: Total ten male participants with in the age group of 9-13 years, with type-d personality were recruited in the study. OM followed by Raga Bhairavi intervention was given once a day for 12 weeks and post intervention values were collected after 12 weeks. ISMA questionnaire and DASS 42 was used to assess the stress levels.

Results: The results are presented in table 1. There was a significant decrease in the stress scores followed by the intervention. A significant difference is found between the stress scores of subjects before and after the intervention of Raga therapy.

Conclusion: The present provides further evidence for beneficial effects of Raga therapy in the management of stress among children with type-d personality. We recommend further detailed studies in this area with higher sample size and more parameters to recommend inclusion of the Raga therapy as a tool for management of daily life stress.
\end{abstract}

Keywords: Raga therapy, OM chanting, Type D personality, Raga, Raga therapy, Stress management.

\section{Introduction}

Stress is a non-specific and generalized response of the body to any demand made on the body. Stress is unavoidable now a days and hence it must be managed effectively. ${ }^{1-3}$ Screening of stress must be performed on regular basis from school levels to identify the vulnerable population and must be addressed professionally. If the vulnerable population are not provided with effective intervention, they remain depressed throughout the life. There are many stress management procedures available, which may enable a person to diminish their levels of stress. Raga is the arrangement of selected notes (swaras) that allow proper 'mood' or feeling in a specific mix..$^{4-6}$ Listening to music on regular basis is effective as different sounds and notes follow up on human body and mind. Earlier studies demonstrated that practicing Om chanting and Ragas for stress alleviation. Different Ragas are likewise observed to be exceptionally compelling in overseeing or curing illnesses. In such conduct, a blend of particular notes or Ragas is being utilized to follow up on a specific chakra. ${ }^{7}$ It additionally helps in calming nervousness, making unwinding and actuating snoozing. ${ }^{8-10}$ Individuals with negative affectivity and social inhibition were considered as type D personality. As these individuals are having high levels of stress, it is needed to screen and identify at the early stages of life and help them to manage the stress through effective coping methods. Hence, the present study was undertaken to observe the effect of Raga therapy in the treatment of stress in the age group of 9-13 years.

\section{Materials and Methods}

Participants: As the study was undertaken as a pilot study, we have included ten male participants with in the age group of 9-13 years, with type D personality were recruited in the study after obtaining the written informed consent. The self-administered, standard, validated ISMA questionnaire was used to assess the stress levels before and after the intervention. A coordinator who is not involved in the study helped the students to fill the questionnaire the study was approved by institutional ethical committee. Participants were screened with DS-14 scale to identify type-d personality.

\section{Methods}

ISMA Stress Questionnaire: The International Stress Management Association (ISMA), questionnaire consists of 25 items to assess the stress levels. It was available at the website of the association. Permission was obtained to use the questionnaire prior to the study. DASS Questionnaire: DASS 42 questionnaires was used to assess the negative emotional stares of depression, anxiety and stress. ${ }^{11}$

Intervention: The total duration of intervention was 15 minutes. First 5 minutes listening to OM followed by Raga Bhairavi. The intervention was given once a day for 12 weeks and post intervention values were collected after 12 weeks. The intervention was administered at 9 am in the morning as per the convenience of the participants. 
Data analysis: Data was analyzed by using SPSS 20.0. Student $t$ test was used to observe the significance of difference between the groups. $\mathrm{P}$ value less than 0.05 was considered as significant.

\section{Results}

The results are presented in table 1 . There was a significant decrease in the stress scores followed by the intervention. A significant difference is found between the stress scores of subjects before and after the intervention of Raga therapy.

Table 1: Pre and post-intervention Mean, SD and $t$ score of stress

\begin{tabular}{|l|c|c|c|}
\hline Parameter & Pre-intervention score & Post- intervention score & P value \\
\hline Stress score & $14.26 \pm 3.51$ & $10.55 \pm 2.88$ & $0.0187^{*}$ \\
\hline $\begin{array}{l}\text { DASS Depression } \\
\text { score }\end{array}$ & $14 \pm 3$ & $9 \pm 4.23$ & $0.0069^{*}$ \\
\hline DASS Anxiety score & $12 \pm 4$ & $7 \pm 2.77$ & $0.0044^{*}$ \\
\hline DASS Stress score & $16 \pm 5.61$ & $9 \pm 3.67$ & $0.0040^{*}$ \\
\hline
\end{tabular}

*This difference is considered to be statistically significant

\section{Discussion}

Stress has reached epidemic proportions due to our fast-paced life-style and the consequent excessive demands on our bodies. Our study was aimed to show how Raga therapy helps in relieving stress and we found that there was significant reduction in stress scores after intervention. ${ }^{12}$ Similar results were seen in a study by Beck et al, Baste VS et al which showed that music therapy significantly improved perceived stress, well-being, mood disturbance, depression, anxiety, and physical distress symptoms. ${ }^{13,14}$

Studies have shown that while listening to music, dopamine is released onto the nucleus accumbens, an area classically thought to mediate reward perception and addiction. ${ }^{15}$

It was observed that pleasant music stimulated the inferior frontal gyrus and Rolandic operculum which reflect working memory. Pleasant (contrasted to unpleasant) music showed activations of the inferior frontal gyrus (IFG, inferior Brodmann's area (BA) 44, BA 45, and BA 46), the anterior superior insula, the ventral striatum, Heschl's gyrus, and the Rolandic operculum. IFG activations appear to reflect processes of music syntactic analysis and working memory operations. ${ }^{15}$

Living systems show sensitivity to specific radiant energies -be it acoustical, magnetic or electromagnetic. As the impact of music could be easily gauged on emotions and thereby on mind, it can be used as a tool to control the physiological, psychological and even social activities of the patients. Some Ragas like Darbari Kanhada, Kamaj and Pooriya are found to help in defusing mental tension, particularly in the case of hysterics. The immense potential of the power of Shabda (cosmic flow of sound) hidden in music was well recognised by the ancient Indian sages and they had devised several musical patterns emanating from the "Omkara" for chanting of the Vedic hymns and for distinct spiritual effects. Singing or engrossed listening of Raga Bhairavi has been found to uproot the diseases of kapha dosha e.g. asthma, chronic cold, cough, tuberculosis, some of the sinus and chest related problem. ${ }^{16}$ Good and his colleagues investigated the effect of relaxation, music, and the combination of relaxation and music on postoperative pain across between 2 days and two activities (ambulation and rest) and across ambulation each day. ${ }^{17}$ Bonny has suggested a series of musical selections for tape recordings, which can be chosen for their sedative effects, according to other mood criteria, associative imagery, and relaxation potential; none of which have been empirically confirmed. ${ }^{18}$ There is a decreased systolic blood pressure and a beneficial mood change from anxiety to relaxed and calm mood when sedative music is played. ${ }^{19}$ Bolwerk set out to relieve the state anxiety of patients in a myocardial infarction ward using recorded classical music. ${ }^{20}$

\section{Conclusion}

The present provides further evidence for beneficial effects of Raga therapy in the management of stress among children with type-d personality. We recommend further detailed studies in this area with higher sample size and more parameters to recommend inclusion of the Raga therapy as a tool for management of daily life stress.

\section{Conflicts of Interest: Nil}

\section{References}

1. Arieh Y. Shalev, Posttraumatic Stress Disorder and Stress-Related Disorders, Psychiatr Clin North Am. 2009;32(3):687-704.

2. Bouma, E.M., Ormel, J., Verhulst, F.C., \& Oldehinkel, A.J. Stressful life events and depressive problems in early adolescent boys and girls: The influence of parental depression, temperament and family environment. $J$ Affect Dis. 2008;105:185-93.

3. Gillespie, C.F., \& Nemeroff, C.B. (2007), Corticotropinreleasing factor and the psychobiology of early life stress. Curr Dis Psychol Sci. 2007;16(2):85-89.

4. Jang, K.L., Thordarson, D.S., Stein, M.B., Cohan, S. L., \& Taylor, S. (2007). Coping styles and personality: A biometric analysis. Anxiety Stress Coping. 2007 Mar;20(1):17-24. 
5. Lupien, S.J., McEwen, B.S., Gunnar, M.R., \& Heim, C. Effects of stress throughout the lifespan on the brain, behavior, and cognition. Nat Rev Neurosci. 2009; 10(6):434-45.

6. Monroe, SM, Modern approaches to conceptualizing and measuring human life stress, Anпи Rev Clin Psychol. 2008;4:33-52.

7. Raj K, Rinchhen CZ and Vishwajeet V. (1989). Ringe. Stress reduction through listening to Indian classical music during gastroscopy. Diagn Ther Endosc. 1989;4(4)191-197.

8. Speilberger, Charles, D., Reheiser, Eric, C. The job stress survey: Measuring gender differences in occupational stress. Journal of Social Behavior \& Personality.1994; 9(2)199-218.

9. Taylor, S.E., Stanton, A.L. Coping resources, coping, processes, and mental health. Annu Rev Clin Psychol. 2007;3:377-401.

10. Uma G and Gupta BS. Psychophysiological responsivity to Indian instrumental Music, Psychology of Music. 2005;33(4):363-372.

11. Lovibond, S.H. \&Lovibond, P.f. Manual for the Depression anxiety Stress Scales.1995; (2nd Ed) Sydney: Psychology Foundation.

12. Deekshitulu. Stress Management for Mantra Techniques. MOJ Yoga Physical Ther. 2017;2(2):1-4.

13. Beck BD, Hansen ÅM, Gold C. Coping with WorkRelated Stress through Guided Imagery and Music (GIM): Randomized Controlled Trial. J Music Ther. 2015;52(3):323-52.
14. Baste VS, Gadkari JV. Study of stress, self-esteem and depression in medical students and effect of music on perceived stress. Indian J Physiol Pharmacol. 2014;58(3):298-301.

15. Koelsch S. Towards a neural basis of music-evoked emotions. Trends Cogn Sci. 2010;14(3):131-137.

16. Joyanta Sarkar, Utpal Biswas. An effect of Raga Therapy on our human body. International Journal of Humanities and Social Science Research. November 2015;1(1):4043.

17. Good M, Stanton-Hicks M, Grass JA, Anderson GC, Lai HL, Roykulcharoen V, Adler PA. Relaxation and music to reduce postsurgical pain. J Adv Nurs. 2001 Jan;33(2):208-15.

18. Bonny H, McCarron N (1984) Music as an adjunct to anaesthesia in operative procedures. J Am Assoc Nurse Anesth. 55-57.

19. Updike P. Music therapy results for ICU patients. Dimens Crit Care Nurs. 1990 Jan-Feb; 9(1):39-45.

20. Bolwerk CA. Effects of relaxing music on state anxiety in myocardial infarction patients. Crit Care Nurs Q. 1990 Sep;13(2):63-72.

How to cite this article: Madhusudhan U, Kumar SS, Jabir PK. Beneficial effects of Raga therapy in the management of stress among children with type D personality. Ind J Clin Anat Physiol. 2018;5(3):347-349. 